\title{
A NEW APPROACH FOR AIRLINE REVENUE MANAGEMENT: TOTAL REVENUE BOUNDARIES
}

\author{
DOI: 10.17261/Pressacademia.2020.1214 \\ JBEF- V.9-ISS.2-2020(1)-p.62-67
}

\author{
Asli Emine Ertugrul, Ramazan Sahin \\ Turkiye Is Bankasi, Data Management Department, Tuzla, Istanbul, Turkey. \\ asliemineertugrul@gmail.com , ORCID: 0000-0002-4104-1103 \\ Gazi University, Industrial Engineering Department, Maltepe, Ankara, Turkey. \\ rsahin@gazi.edu.tr, ORCID: 0000-0001-7074-4038
}

Date Received: February 26, 2020

Date Accepted: May 12, 2020

To cite this document

Ertugrul, A.E., Sahin, R., (2020). A new approach for airline revenue management: total revenue boundaries. Journal of Business, Economics and Finance (JBEF), V.9(2), p.62-67.

Permanent link to this document: http://doi.org/10.17261/Pressacademia.2020.1214

Copyright: Published by PressAcademia and limited licensed re-use rights only.

\begin{abstract}
Purpose - The purpose of the paper is developing and testing an advanced version of an existing method in the literature, which is used for airline revenue management (ARM).

Methodology - Expected marginal seat revenue (EMSR) is the mostly used heuristic revenue management model for literature and real life problems. In the paper, EMSR is developed, and an advanced heuristic method is formed. The new method is called total revenue boundaries (TRB). The method is tested by a problem and compared with EMSRa, EMSRb and EMSRc, which are three types of EMSR in the literature. Findings- According to the results, TRB outperforms than EMSRa, EMSRb and EMSRc. It gives higher revenue levels with higher load factors. Conclusion- At the end of the study, the most common ARM method is improved. By this way, a new heuristic model is gained, which does not need complicated calculations. TRB keeps the uncomplicated nature of EMSR but gives better results.
\end{abstract}

Keywords: Airline revenue management, total revenue boundary, expected marginal seat revenue (EMSR), optimization, seat inventory management.

JEL Codes: C61, R40, R49

*This article is the extended version of Total Revenue Boundaries for Determining Booking Limits in Airline Revenue Management presented in 5. International Conference on Engineering Sciences Ankara 2019.

\section{INTRODUCTION}

Some companies apply for revenue management tools for the optimization of their revenues like hotels, airlines and cruise lines. Because, their products are not tangible and cannot be stocked. An empty hotel room for a night or an empty seat in a flight is gone when the night or flight is over. That is why, these limited product resources should be sold as efficiently as possible. In order to ensure the efficiency, revenue management methods are applied by companies.

Airline industry is an expensive environment. Initial investment and operating cost rates are so high. In the study of Gelirli (2019), it is mentioned that airlines prefer to lease their aircraft to avoid big initial investments, decrease risk, to access the latest technology and etc. Leasing the aircraft is one of the ways that they use to make profit. Another method which airlines apply is managing their revenues to maximize it. Airline revenue management (ARM) studies generally focus on two main areas: pricing and seat inventory management. As for seat inventory management for ARM, there are three main subtitles worked on by scientists and experts: overbooking, fare class mix and origin - destination control (Belobaba, 2015). In overbooking problems, scientists try to assign authorized capacity of a flight. On the other hand, fare class mix and origin-destination (OD) control problems handles optimal flight ticket distribution in a flight or flight in the network. The studies about ARM started up in 1970s firstly in American Airlines. Thanks to the success of American Airlines in ARM applications, the latter attracted attention of airlines and scientists. Since then, airlines and scientists have been working on ARM with a view to developing new methodologies and 
algorithms. There are heuristics, dynamic and linear methods in the literature for ARM, which yields efficient results. A new heuristic method is to be developed in this paper. In addition, it is going to be experimented and compared by some numerical examples.

This paper is developed based on the study of Ertuğrul and Şahin (2019) and expanded in accordance. The outline of the paper continuous with literature review. In the third section, the methodology of the paper is explained while under the fourth section, numerical examples are provided. The results thereof are going to be discussed under the same section, as well. The paper ends with a conclusion section, where the review of the study and recommendations for further studies are provided.

\section{LITERATURE REVIEW}

Revenue management and especially ARM are studied by many scientists. Hundreds of papers and studies can be found in the literature. However, there are some basic resources, that explains the logic of revenue management and its applications, in the literature (Belobaba , 2015), (Talluri \& van Ryzin, 2004), (Phillips, 2005).

As has been already stated, the studies about ARM started up in 1970s in the United States. Starting therefrom, many researches and studies have been conducted by scientists and airlines. The first and most important studies in this regard belonged to Littlewood (1972) and Belobaba (1987). Littlewood developed Littlewood's rule and Belobaba expanded the rule by the method of expected marginal seat revenue (EMSR). In the following years, EMSR was renewed by Belobaba's another research paper (1992) as EMSRb. Later in the years, many studies were published about EMSR. Some of them developed new EMSR versions while others applied EMSR for model comparison (Boyd \& Kallasen, 2004), (Weatherford, 2004), (Frank \& Friedemann, 2009), (Fiig, Isler, Hopperstad, \& Belobaba, 2010), (Tavana \& Weatherford, 2017). One of the newest studies about EMSR belongs to Banciu, Odegaard and Stanciu (2019). In their paper, dependency between fare levels is considered while the original EMSR calculates booking limits with the assumption of independency between fare levels. In addition, different distributions for the demand are tried in their study.

Seat inventory management models makes decision on whether to accept or reject arrival customers based on the inputs of the system. For this decision process, there are not just heuristic models. Dynamic programming, bid price control or linear programming are also very popular methods for seat inventory management. To examine the logic of the dynamic programming for ARM, the book of Talluri and Van Ryzin (2004) or the study of Chapuis (2008) could be perused. Lee and Hersh (1993) carried out a study about dynamic programming of seat inventory control, as well, which has been one of the first and most popular studies. Another detailed study on dynamic programming belong to El-Haber and Al-Taha (2004). In their article, a Markov decision process has been developed for a two-leg flight, which defines the booking limits dynamically. There are also many other detailed studies about dynamic programming in the literature (Huanga \& Liang, 2011), (Elmaghraby \& Keskinocak, 2003), (Wright, Groenevelt, \& Shumsky, 2010). One another common method for ARM is bid price control, which is used for network revenue management. Bid price control determines a price limit for each leg of a networked flight. According to the logic of the algorithm, the price of a flight ticket cannot be less than the total of the bid prices of flight legs. Studies about bid price control can be about determination or control of bid price in an ARM model. One of the recent studies about the bid price was carried out by Hosseinalifam et al. (2016). This study brought in a new and changeable customer choice-based mathematical model for the prediction of the bid prices. Another example for bid price control belongs to Topaloğlu (2008). He made a research about a new method of computing bid prices, which is called SDD. Topaloglu (2009) used lagrangian relaxation for bid price determination in another paper, that calculates bid prices according to the left number of seats and time to departure. Linear programming is also an option for ARM problems. However, it is generally used for finding initial solutions (Talluri \& van Ryzin, 2004). Stochastic methods are also applied for ARM. Zhang and Cooper (2005) have a study about simultaneous seat inventory control, and they implement a stochastic method to develop their algorithm.

Apart from all these, there are new methods, ideas or studies that have different angels in the ARM literature. In the study of Lardeux et al. (2019) idea of buy-back the flight tickets and reselling them in a case of demand increasing is handled. On the other hand, some scientists prefer to study about ARM for a specific region like Yazdi, Kaviani, Hanne and Ramos (2020). Their study is developed for a case about an airline in Iran and the airline company's flight operations. Also, there are papers, which make some arguments about the ARM applications in airline markets (Belobaba, 2011), (Aslani, Modarres, \& Sibdari, 2014), (Kramer, Friesen, \& Shelton, 2018). 


\section{DATA AND METHODOLOGY}

In this study, a new revenue management model, which is called total revenue boundaries (TRB), is built and examined for an ARM seat inventory problem. Similar to a regular ARM system, TRB determines whether to accept or reject arriving passengers. Every ARM system has its own logic, booking limit or bid price for this decision process. TRB has also a logic or limitation or such kind of bid price, through which it makes a decision on whether to reject or accept an arriving passenger. In this algorithm, the decision variable is $x$. It is a binary decision variable, which means 0 or 1 . The system has a sales period, signified by $T$. The period is divided into $t$ sub-periods, and at most one sale can occur in each t. There are three check points to control the total revenue. Since business travelers, who are flexible in price, tend to purchase their flight tickets close to the departure time, check points are placed periodically in the last sections of $\mathrm{T}$. In addition, the model is based on single-leg flight.

As can be understood from the name of the model itself, TRB functions according to some total revenue boundaries, which are predetermined. On some points of the sale period, TRB checks if the total revenue boundary is reached or not. If it is not reached, the system closes the sale of the cheapest fare level that is available. Otherwise, TRB does not change anything in the system. For example, the first total revenue boundary is $\$ 10,000$. In the first check point, TRB controls if the total gained revenue until that moment is less or greater than the boundary. If total revenue is less than or equal to $\$ 10,000$, TRB closes the sale of the lowest fare level tickets. Otherwise, it does not change anything. Mathematical explanation of the model exists on the Equation (1).

If $\sum_{t=1}^{T} \sum_{i=1}^{n} x_{i t} F_{i} b_{i t} \leq r_{t}$, then $\sum_{t}^{T} x_{i_{k} t}=0$

where

$i$ - fare level;

$F_{i}$-ticket price of fare level i;

$b_{i t}$ - number of seats sold by fare level $\mathrm{i}$ at time $\mathrm{t}$;

$k$ - number of fare levels available for sale;

$i_{k}$ - cheapest fare level available for sale;

$l$ - number of total revenue boundaries.

Each passenger buys his/her flight ticket from the fare level that they can afford. In the literature, there are two kinds of demand structure (Tavana \& Weatherford, 2017), (Boyd \& Kallasen, 2004). In the paper of Boyd and Kallasen (2004), these two demand structures are determined as yieldable and priceable. For the yieldable demand, passengers purchase the ticket from the fare level that they are interested in even when there is a cheaper one. If there is no available seat for their fare level, they are denied. On the other hand, for the priceable demand, passengers try to buy their flight tickets as cheap as possible. If there is an available seat in a fare level the price of which does not exceed their willingness to pay, passengers purchase the flight ticket. Tavana and Weatherford (2017) describe yieldable demand as restricted while priceable demand is defined unrestricted. They also state that the demand in real life is between restricted and unrestricted structure. In TRB, the demand structure is restricted, which means every passenger purchases the flight ticket that $s /$ he is interested in. In addition, the model accepts that there are enough passengers in the market, so there are new arriving people instead of rejected ones.

\section{HYPOTHETICAL APPROACH}

In this section, TRB will be examined by a numerical example. The same example is also going to be applied for EMSRa, EMSRb and EMSRc. As it is mentioned above, EMSRa and EMSRb are two models developed by Belobaba in 1987 and 1992 . The third EMSR model, which is called EMSRc, is a new version of EMSR. It is developed by Tavana and Weatherford (2017). The logic of EMSRc is as easy as EMSRb and EMSRc. In the article of Tavana and Weatherford, it is proved that EMSRc outperforms than EMSRa and EMSRc under some certain conditions.

There are four different fare levels in the example, which are shown in the Table 1 . The demands for each fare level are normally distributed. In addition, there are 150 seats in the aircraft. 
Table 1: Fare Levels and Ticket Prices

\begin{tabular}{cc}
\hline Fare Level & Ticket Price \\
\hline Y & 500 \\
\hline B & 420 \\
\hline M & 290 \\
\hline Q & 125 \\
\hline
\end{tabular}

As has been mentioned before, there are three check points during T. The first check is made at $\mathrm{t}=140$ by total revenue of $\$ 42,000$ (these points are found by trial and error method). The second and third check points exist on $t=150$ and $t=160$. The revenue limits are calculated according to the approximate income of 10 seats. Extra income coming from the sale of 10 more seats is added to $\$ 42,000$ and the new limits are experienced. After that, the limits are increased systematically. It is seen that while the revenue limits are increasing, the total revenue is increasing until a certain point, as well. In the end, the revenue limits are determined as $\$ 42,000-\$ 45,000-\$ 49,000$.

An example as below can be further examined in order to apprehend the functioning logic of TRB more clearly: In the first check point, total revenue is checked to understand whether it is greater than $\$ 42,000$ or not. All passengers coming for $Q$ fare level are rejected after $\mathrm{t}=140$ if the first total revenue condition is not provided. When it comes to the second limit, the system starts to reject both $B$ and $Q$ fare customers if the limit is not achieved. In the last condition, only $Y$ fare passengers are accepted in the case where the revenue cannot reach $\$ 49,000$.

For all fare levels, there are individual demand data which represent the normal distribution shown in the Table 2 . According to these data, random demand numbers are created. 20 different demand scenarios are built. As ensuring the accuracy for the performance measurement of the models is desired, the same scenario's data are used for the simulations of all the models (TRB, EMSRa and EMSRb). All the ARM systems are built and run on Microsoft Visual Studio Express 2015 for Windows. They are run, and the results are recorded. Each model has an approximate total revenue and load factor. As it is seen on Table 3, TRB outperforms EMRSa EMSRb and EMSRc. In addition, the load factor of TRB is significantly greater than the other ARM models.

Table 2: Mean Demand and Standard Deviation Values of Fare Levels

\begin{tabular}{ccc}
\hline Fare Level & Mean Demand & Standard Deviation \\
\hline $\mathrm{Y}$ & 16,5 & 5,6 \\
\hline $\mathrm{B}$ & 44,2 & 15 \\
\hline $\mathrm{M}$ & 35,1 & 11,2 \\
\hline $\mathrm{Q}$ & 55,0 & 9,3 \\
\hline
\end{tabular}

Table 3: Results of Numerical Example for Each ARM Model

\begin{tabular}{ccccc}
\hline ARM Model & Approximate Mean & Approximate Load Factors & Maximum Revenue & Minimum Revenue \\
\hline TRB & $\$ 45.623,25$ & 149,9 & $\$ 53.860,00$ & $\$ 35.380,00$ \\
\hline EMSRa & $\$ 45.494,75$ & 140,7 & $\$ 53.860,00$ & $\$ 33.005,00$ \\
\hline EMSRb & $\$ 45.571,50$ & 147,5 & $\$ 53.860,00$ & $\$ 30.825,00$ \\
\hline EMSRc & $\$ 44.978,00$ & 131,6 & $\$ 51.810,00$ & $\$ 29.190,00$
\end{tabular}

As it is seen on the results table, TRB gives good result numerically, which makes the airline earn more revenue. Besides the results, there are more advantages of TRB to mention. By the development of TRB, a new and useful model, which performs better than the most common models in the literature, is gained. At the same time, this new model does not require complicated calculations like bid price control or dynamic programming. Therefore, TRB can be an advantageous ARM tool for both literature experiments and business applications. TRB differs than the other ARM models by its limitation logic. While the EMSRa, $b$ and $c$ 
are looking for number of seat limitation, TRB is determining the limits according to the revenue level. Also, the limitation rules become invalid when the constrained is provided. By this method, TRB can reach higher load factors.

\section{CONCLUSION}

Revenue management is a kind of business method, which is applied by companies whose product cannot be stocked. These companies must manage their product inventory to sell them by the most effective and efficient way. Airlines are one of these companies and ARM methods are studied and searched by scientists and airlines for about 50 years. In this study, a new model for ARM, TRB has been developed. TRB decides to accept or reject an arrival passenger just like the other ARM models. However, TRB has some different features than the other ARM models. TRB defines limitation points according to the number of fare levels just like EMSR. On the other hand, our model does not set limitations on the number of seats. Instead, it defines boundaries on total revenue. From this perspective, TRB is similar with bid price control but our model does not need so much calculations like bid price control.

Proposed TRB method is tested with 20 flight ticket sale scenarios. The same scenarios are applied to the other ARM methods to make a comparison. EMSR is selected for this comparison because it is the most common and mostly applied ARM method. Since EMSR has two types, which are EMSRa and EMSRb, TRB has been compared with two of them. In addition, a new version of EMSR, which is EMSRc, is experimented. The results demonstrate that TRB yields higher revenue levels than EMSRa, EMSRb and EMSRc. In addition, the load factor result of TRB is better than all EMSR models. Therefore, proposed TRB method for the ARM in this paper, which is easy to understand and apply, and requires not many calculations, has been developed.

For further studies, the determination of the boundaries and check points can be ensured by a definitive algorithm instead of trial determination. Additionally, in the algorithm of TRB, the number of total revenue boundaries is settled by number of fare level in the problem (I=n-1). In an advanced version of TRB, the number of the boundaries may be increased systematically for a better total revenue control. Besides, TRB can be compared with the same models under different conditions to handle the performance of the model deeper. Another comparison test may be done with other popular ARM algorithms like bid price control or dynamic programming.

\section{REFERENCES}

Aslani, S., Modarres, M., \& Sibdari, S. (2014). On the fairness of airlines' ticket pricing as a result of revenue management techniques. Journal of Air Transport Management, 56-64. DOI: 10.1016/j.jairtraman.2014.05.004

Banciu, M., Odegaard, F., \& Stanciu, A. (2019). Distribution-free bounds for the expected marginal seat revenue heuristic with dependent demands. Journal of Revenue and Pricing Management, 155-163. DOI: 10.1057/s41272-018-00170-6

Belobaba, P. (2015). Airline Revenue Management. P. Belobaba, A. Odoni, \& C. Barnhart, The Global Airline Industry. Wiley.

Belobaba, P. (1987). Air Travel Demand and Airline Seat Inventory Management. Doctor of Philosphy. United States of America: Massachusetts Institute of Technology.

Belobaba, P. (1992). Optimal vs. Heuricstic Methods for Nested Seat Allocation. Proceedings of AGIFORS Reservations and Yield Management Study Group (s. 28-53). Brussels: AGIFORS.

Belobaba, P. (2011). Did LCCs save airline revenue management. Journal of Revenue and Pricing Management, 19-22. DOI: doi.org/10.1057/rpm.2010.45

Boyd, E. A., \& Kallasen, R. (2004). Practice Papers: The science of revenue management when passengers purchase the lowest available fare. Journal of Revenue and Pricing Management, 171-177. DOI: 10.1057/palgrave.rpm.5170104

Chapuis, J. M. (2008). Basics of Dynamic Programming for Revenue Management. Revenue Yield Management eJournal, 21.

El-Haber, S., \& El-Taha, M. (2004). Dynamic two-leg airline seat inventory control with overbooking, cancellations and no-shows. Journal of Revenue and Pricing Management, 143-170. DOI: 10.1057/palgrave.rpm.5170103

Elmaghraby, W., \& Keskinocak, P. (2003). Dynamic Pricing in the Presence of Inventory Considerations: Research Overview, Current Practices, and Future Directions. Management Science, 1287-1309. DOI: 10.1287/mnsc.49.10.1287.17315 
Ertuğrul, A. E., \& Şahin, R. (2019). Total Revenue Boundaries for Determining Booking Limits in Airline Revenue Management. 5th International Conference on Engineering Sciences. Ankara.

Fiig, T., Isler, K., Hopperstad, C., \& Belobaba, P. (2010). Optimization of mixed fare structures: Theory and applications. Journal of Revenue and Pricing Management, 152-170. DOI: 10.1057/rpm.2009.18

Frank, M., \& Friedemann, M. (2009). A simulation study: comparing the Markov decision process approach to the expected marginal seat revenue $b$ heuristic under differing demand behaviour. International Journal of Revenue Management, 133-147. DOI:

10.1504/IJRM.2009.024161

Gelirli, N. (2019). Analysis of Financial Implications Due to Absence of Indegenous Aircraft Leasing Enterprice in Turkey. Journal of Business, Economics and Finance, 235-246. DOI: 10.17261/Pressacademia.2019.1167

Hosseinalifam, M., Marcotte, P., \& Savard, G. (2016). A new bid price approach to dynamic resource allocation in network revenue management. European Journal of Operational Research, 142-150. DOI: 10.1016/j.ejor.2016.04.057

Huanga, K., \& Liang, Y.-T. (2011). A dynamic programming algorithm based on expected revenue approximation for the network revenue management problem. Transportation Research Part E: Logistics and Transportation Review, 333-341. DOI: 10.1016/j.tre.2010.11.005

Kramer, A., Friesen, M., \& Shelton, T. (2018). Are airline passengers ready for personalized dynamic pricing? Journal of Revenue and Pricing Management, 115-120. DOI: 10.1057/s41272-017-0122-0

Lardeux, B., Sabatier, G., Delahaye, T., \& Boudia, M. (2019). Yield optimization for airlines from ticket resell. Journal of Revenue and Pricing Management, 213-227. DOI: 10.1057/s41272-018-00167-1

Lee, T. C., \& Hersh, M. (1993). A Model for Dynamic Airline Seat Inventory Control with Multiple Seat Bookings. Transportation Science, $252-265$. DOI: $10.1287 /$ trsc.27.3.252

Littlewood, K. (1972). Forecasting and Control of Passenger Bookings. AGIFORS Symposium Proc. (s. 95-117). Nathanya: AGIFORS Symposium Proc.

Phillips, R. L. (2005). Pricing and Revenue Optimization. Stanford, California: Stanford University Press.

Talluri, K., \& van Ryzin, G. (2004). The Theory and Practice of Revenue Management. Boston: Kluwer Academic Publishers.

Tavana, H., \& Weatherford, L. (2017). Application of an alternative expected marginal seat revenue method. Journal of Air Transport Management, 65-77. DOI: 10.1016/j.jairtraman.2017.02.006

Topaloğlu, H. (2008). A Stochastic Approximation Method to Compute Bid Prices in Network Revenue Management Problems. INFORMS Journal on Computing, 596-610. DOI: 10.1287/ijoc.1080.0269

Topaloğlu, H. (2009). Using Lagrangian Relaxation to Compute Capacity-Dependent Bid Prices in Network Revenue Management. Operations Research, 637-649. DOI: 10.1287/opre.1080.0597

Weatherford, L. (2004). EMSR versus EMSU: Revenue or utility? Journal of Revenue and Pricing Management, 277-284. DOI: $10.1057 /$ palgrave.rpm.5170114

Wright, C. P., Groenevelt, H., \& Shumsky, R. A. (2010). Dynamic Revenue Management in Airline Alliances. Transportation Science, 15-37. DOI: $10.1287 / \operatorname{trsc} .1090 .0300$

Yazdi, A. K., Kaviani, M. A., Hanne, T., \& Ramos, A. (2020). A binary differential evolution algorithm for airline revenue management: a case study. Soft Computing. DOI: 10.1007/s00500-020-04790-2

Zhang, D., \& Cooper, W. L. (2005). Dan Zhang, William L. Cooper. Operations Research, 415-431. DOI: 10.1287/opre.1050.0194 